\title{
Web based Remotely Accessible ES-Enabled Information Centre for Rural Farmer
}

\author{
Nitin Katkamwar \\ Research Scholar, Inter Institutional Computer \\ Centre, RTM Nagpur University, \\ Maharashtra India
}

\author{
Keshao Kalaskar \\ Professor, Ambedkar College Chandrapur, \\ Maharashtra, India
}

\begin{abstract}
Based on internet and artificial intelligence (AI) techniques to build Web-Based Remotely Accessible Expert SystemEnabled Information Centre for Rural Former, can provide expert-level advice and diagnosis services that help to optimize the crop production for rural Farmer particularly in India. The basic structure and related key technology for Advice and diagnosis Expert System is introduced in this paper. The architecture of an open web based and EIS enabled Advice and diagnosis expert system was brought out. A practical knowledgebase update model was analyzed and designed. The working methodology and process of the system were also designed and explained, which will gives basics ides for the development of practical and reliable Webbased Remotely Accessible Expert System Enabled Information Centre (WRAESEIC) for Rural Former.
\end{abstract}

\section{Keywords}

Remote Diagnosis System; Agriculture Advisory System remote advice; expert system; system architecture; knowledgebase update; information centre; Rural Agriculture.

\section{INTRODUCTION}

India is identified as agricultural country in the world. There are so many types of crops producing by farmer; Indian agriculture can be categorized into the urban agriculture and rural agriculture depending on their cultivation technology and methodology. "However, the relationship between urban and rural sectors in many developing countries is still characterized by an economic dualism, in other words, by the coexistence of a modern urban sector and a traditional rural sector. This duality arose because many developing countries, including China and India, pursued a heavy industrialization development strategy based on the transfer of resources and labor surpluses from the traditional (or rural) sector to the modern (or urban) sector. This development strategy largely favored the development and growth of the urban sector at the expense of rural areas" [2]

The urban former are literate and uses the recent technology and methods to optimize the crop production whereas the rural formers are illiterate and they are not much aware about recent technology, they uses traditional methods and resulting in loss of crop production. There is need to provide recent technology up to rural areas to support rural uneducated former by developing and implementing Web-Based Remotely Accessible Expert System-Enabled Information Centre (WRAESEIC). The Information Centre is Remote centre in the small villages and town that access the centralized Agriculture Expert System connected through Internet. Through the Information Centre, Farmer will get the all possible information and guidelines like recent cultivation methods, whether forecast, exact timing for cultivation, uses and amount of Pesticides, uses and amount of Fertilizers, possible Irrigation methods, Different government schemes for financial supports using user friendly communication tools like audio visual communication or by Information Centre Representative .

The paper first introduces WRAISEIC and realization of its need. Then based on this, the Expert System technique is introduced to combine remotely Accessible Information Centre. So the Web-Based Remotely Accessible Expert System-Enabled Information Centre (WRAESEIC) is constructed. The architecture and key techniques for realization are also researched in the paper. In this paper, architecture section describes the overall structure of Remotely Accessible Information Centre. It introduces Expert System technique and provides the system architecture of an open remotely Accessible Centralized expert system.

\section{CURRENT SCENARIO OF AGRICULTURE IN INDIA}

Indian agriculture is the largest private sector enterprise in the country of over 110 million farmers. It engages two-third of total workforce, contributes to 26 per cent of the GDP and nearly one-sixth of the total export earnings. India inherited a stagnant agriculture at the time of independence growing at an annual rate of growth of 0.3 per cent in the first half of the last century. Due to the planned Government policies, technological support provided by agricultural scientists and hard work put in by the farmers, Indian agriculture has achieved an annual growth rate of 2.7 per cent in the post independence era. During the decade of 1980's the growth in food grain production was most impressive at about 3.7 per cent compared to population growth of 2.2 per cent. Unfortunately, it slowed down in nineties to 1.8 per cent, lower than the population growth of 2 per cent. Further, within the agriculture sector too, the development has been uneven in production and productivity across regions and crops [22].

The key macro indicator of national achievement in agriculture comprised a quantum jump in food grain production from 50.8 million tons in $1950-51$ to 212 million tons in 2000-2001. It is worth noting that 92 per cent of the increase in production has been technology-led [22].

\section{RELATED RESEARCH}

This Section summarizes some of the recent advances and need of advancement in rural development, particularly in the field of precision Agriculture. In the modern India, still the rural are in the agriculture sector, in the article [20] Nidhi Dwivedy has discussed some of the developmental challenges faced by the Indian agriculture sector in particular and developing nations in general - illiteracy, poor socioeconomic conditions, lack of technical knowledge and awareness, small land holdings, modernization leading to barren land and disasters leading to rural poverty, weather-dependent farming systems, low per capita income, underdeveloped physical infrastructures and inefficient bureaucratic procedures associated with the comparatively high cost of agricultural 
production. Natural disasters and human-induced environmental degradation are closely associated with improved farming systems.

A Soil Test Crop Response Based Fertilizer Recommendation Software [11] has been developed by Indian Institute of Soil Sciences, Bhopal, India. It currently provides fertilizer information to 11 states in India which is personalized based on district, soil type, crop, crop variety, season, target, and if available fertility status. In [12], the challenges involved in the development of decision support system to be used by farmers as end user are presented. Sermed and Blackmore in [13], deals with the problem of optimizing irrigation for advantages such as conservation of water and energy, and improvement in the productivity. In [14], authors propose the use of Wireless Sensor Networks on the Australian agriculture fields to automate and optimize the irrigation to withstand the loss of water due to below average rainfall. In Agrisens project [15], Wireless Sensor Network (WSN) had been deployed at Sula vineyard, Nasik, India, for precision agriculture. It addresses issues related to the productivity and disease prediction of the grape crop. It also implements the close looped system to automate and optimize the irrigation in the field. In [16], Burrell et al. performs the study of feasibility and impact of sensor network in agriculture by considering the example of a vineyard. The Lofar Agro Project [17] aims to monitor micro-climate in agricultural field using distributed computing in WSN. A decision support system (DSS) was proposed for providing insights to the applicability of pesticides, fertilizers, tillage and sowing rate. In [18], sensor network has been used to monitor climate, soil, pasture and animals and to form a closed loop control system. In [19], the mKRISHI project aims to bridge the gap between farmers, agricultural experts, financial institutions, soil testing labs, agriculture market and other agriculture related institutions. Bhushan G. Jagyasi, Arun K. Pande, Ramesh Jain proposed a novel experiential computing approach for the mKRISHI framework which aims to provide more insights to an expert by capturing, detecting, storing and analyzing the history of various events in agriculture.

Many researches have been done in the area of agriculture; expert systems have been applied to such problems as crop management, insect control, and productivity considerations for raising a given crop. Farmers and agents from the Department of Agriculture Research Services must make decisions concerning the effective and profitable production of various crops. Expertise for making these decisions exists, but the major problem is making this talent available to the large number of farmers [9]. In [10] Peter J. M ellalieu, Karend Turner, "Expert System for Agricultural Production", A prototype "expert system" is described which ultimately will assist informed lay people to identify the cause of crop damage in agricultural crops and indicate possible treatments. Khumukcham Robindro, Shikhar Kr. Sarma has presented prototype of "JESS Based Expert System Architecture For Diagnosis Of Rice Plant Diseases" in [21] they have presented the importance of the design and development of an expert system for diagnosis of diseases in rice plants. Further, such an expert system is very essential for the farmers as experts are not always available with the farmers and the diseases are one of the important factors for low productivity. When a farmer needs advice of an expert, the expert system would provide the decision support to the farmer.

\section{NEED FOR WRAISEIC}

WRAISEIC is a kind of advanced communication techniques that combines the fault diagnosis technology and computer communication technology to overcome the problems faced by the agriculture sector in INDIA. Some of the basic problems are explained

*Rudimentary infrastructure and policies leads to slow agricultural growth

Slow agricultural growth is a matter of concern as most of India's population is dependent on rural employment for a survival. Current agricultural practices in India are neither economically nor environmentally sustainable and India's yields for many agricultural societies are low. Poorly maintained irrigation methods, illiteracy, lack of technology are among the factors responsible. India has inadequate infrastructure and services because of low investment. Farming equipment and infrastructure are scarce. Because many of the farms are small, the farmers cannot afford irrigation systems and technology that would increase productivity. Low investment in big and small of farms leads to lower production, inefficiency and higher costs, one of the causes of food inflation in India [3].

*Use of technology is inadequate

Adoption of modern agricultural practices and use of latest technology is inadequate In India; farming practices are nonscientific and need some forethought before implementing any new technology. The screening of technology is important since all innovations are not relevant or attractive to all areas. It is important to screen them according to the geographical area and the local context of agriculture and appropriate technologies need to be adopted [3].

\section{*No proper management of irrigation}

Irrigation methods are improper, traditional, and inadequate as there is no effective system management for how much water is stored, how much is used for irrigation or what value can be added to this water. Consequently, farmers depend on rainfall, specifically the Monsoon season. A good monsoon results in robust growth for the economy as a whole, while a poor monsoon leads to sluggish growth.

\section{WHAT IS EXPERT SYSTEM?}

Expert systems have a high-level of knowledge, experience and expertise that cannot be easily transferred to others. They are designed to carry the intelligence and information found in the intellect of experts and provide this knowledge to others for problem-solving purposes [5]. Expert systems capture scarce expert knowledge (expertise). This is an advantage when losing the expert would be a significant loss to the organization. Sharing the expert knowledge improve employee productivity by offering necessary assistance to make the best decision. Improvements in quality frequently appear when expert systems shares expert advice, opinion, and explanation as per requirement. Expert systems are capable of handling enormously complex tasks and activities as well as an extremely rich knowledge-database structure and content. Expert systems can reduce delay in process and errors, as a result, increase output and quality. Additionally, expert systems facilitate the transfer of expertise to remote locations using digital communications technology. In specific situations, ongoing use of an expert system may be cheaper and more consistent than the services of a human expert [6]. Compared to traditional programming Methods, expert system approaches provide the flexibility and 
modifiability with the ability to model rules as data rather than as code. The following are some examples of expert systems which are now in commercial and research use in a number of fields:

*CROP ADVISOR: This is an expert system that performed prescription functions. This expert system is useful to advise cereal grain farmers on appropriate fertilizers and pesticides for their farms. The choice of chemical, amount, and time of application depends on such factors as crop to be grown, previous cropping, soil condition, acidity of soil, and weather. Farmers can access the system via the Internet. Given relevant data, the system produces various financial return projections for different application rates of different pesticides. The system uses statistical reasoning to come to these conclusions. If the question asked is outside the system's expertise, it refers the caller to a human expert. The quality of the advice has become much more uniform, which has increased confidence in the decision taken by farmer [4].

*PLANT: It is used for prediction in agriculture. It forecasts future events, using a model based on past events predicted the damage to be expected when a corn crop was invaded by black cutworm. It was developed by a man called Boulanger, in 1983 [4].

\section{*RICE-CROP Doctor}

National Institute of Agricultural Extension Management has constructed an expert system to diagnose diseases for rice crop and suggest preventive measures [7]

\section{*Farm Advisory System}

Punjab Agricultural University, Ludhiana, has developed the Farm Advisory System to support agriculture. The conversation between the system and the user is like the system asks all the questions from user one by one which it needs to give suggestion on the topic of farm Management [7].

\section{*AGREX}

Center for Informatics Research and Advancement, Kerala has developed an Expert System called AGREX to help the farmer by giving timely and correct advice to the farmers. This Expert System useful for fertilizer application, Irrigation scheduling, and diagnosis of diseases on Rice crop [7]

\section{OVERVIEW OF WRAESEIC APPROACH FOR RURAL AGRICULTURE}

The proposed system is centralized Expert System, which is centrally accessible through the wireless computer network using client server architecture, here Expert system acts as server which is accessed by remotely handled Information Centre, on other hand Information Centre acts as Clients. At the client side, farmers or the representative of Information centre interact with the client interface which is client computer connected to Remote Server of Expert System using Internet over wireless network. This is design of WRAESEIC useful to detect and diagnose crop decease, Advisory system, Farm Scheduling etc. The disease is determined by using a rule base; rules are extracted from experts for different types of crop and their diseases'. The algorithm uses to populate output for symptoms entered by the farmer; it also uses the priority and severity values to determine the disease of crop. Both these results help the diagnostic logic to determine the treatment for the crop with accuracy. Expert from the field of agriculture deals with a complex analysis of all the information gathered about the symptoms. Domain expert's knowledge is gathered to generate rules and stored in the rule base and the rules are fired when there are appropriate symptoms are available.

\subsection{Proposed WRAESEIC architecture}

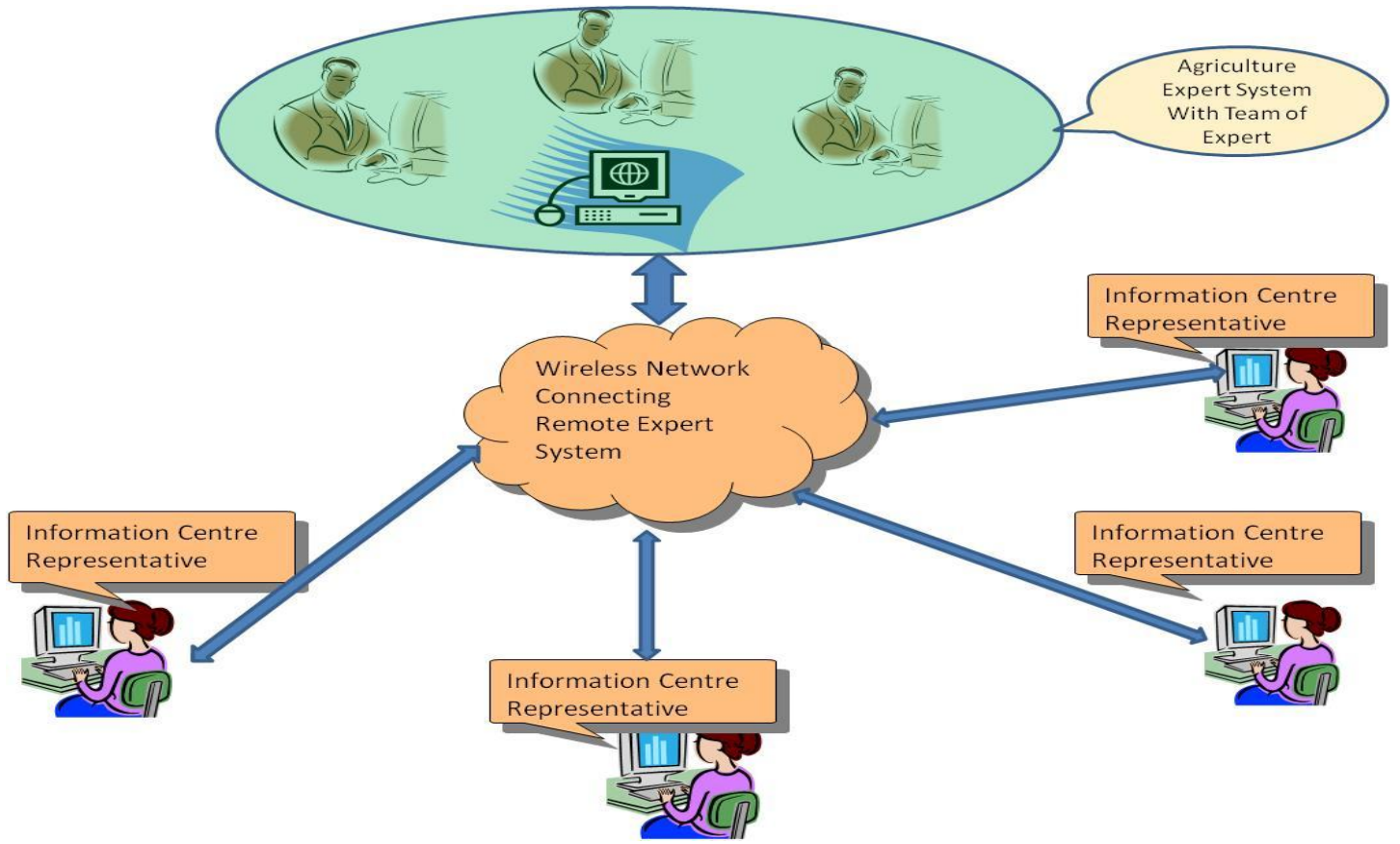

Fig. 1 Proposed Conceptual Client Server Architecture for WRAESEIC 


\subsection{WRAESEIC Interaction with Rural Farmer}

For classifying the events related to WRAESEIC, we propose an client-server based structure (Fig.1) where client represents the agricultural events. In WRAESEIC architecture, the events related to WRAESEIC are defined and classified in the following main categories.

\subsubsection{Farmer's query and Expert's Advice}

Using the WRAESEIC client application at Information Centre, a farmer can raise the query using text, voice, pictures and video with the help of WRAESEIC representative. Any query raised by a farmer is considered as an ES Call.

Similarly, the response of the Expert to the query raised by the farmer can be considered as another ES Call. This event gives the option to an expert to revisit the past similar queries of the farmers; the responses provided to those queries by the experts; the measures taken (actions performed by farmer) and the resultant consequences.

\subsubsection{Actions performed by farmers and Stages in Farming}

The actions of the farmers like spraying of pesticides, application, quantity of fertilizers and irrigation scheduling are considered as events. Further, various stages in farming like transplantation in rice, pruning, sowing, dormant, bud burst, various levels of shoots, various levels of blooms, berry touch, green fruit, variation, colored fruit and harvesting are also considered as events. The information about this category of events can mostly be obtained from the particular farmer itself. In the present WRAESEIC system, a user-friendly system for the farmer allows updating of these types of ES Call.

\subsubsection{Weather Forecasts}

The weather predictions in certain region form another category of ES Call. For example, forecast of excess rainfall may be an important event to be detected, since it helps to take decisions on irrigation, pruning, and applications of pesticides. Thus when informed about the weather forecast events, the farmer may initiate some activity which in turn triggers another set of ES Call. The strong linkages of the weather forecasting events with the expert's decision and farmer's action, makes it more important.

\subsubsection{Composite Events}

Although individual readings based ES Call are useful for farmers to make decisions, most important ES Call are detected by combining observations. Plant disease risk is an example of a composite ES Call. In agriculture literature [23], there exist various crop-specific models to predict the risk of the disease or pest attack on the crop. In [24], presented late blight disease forecasting protocol, by integrating sensor based mathematical disease forecasting models, with human participatory diagnosis using mobile phone application overlay WRAESEIC system. These models require parameters collected using soil, plant, and weather sensors. The risk index obtained will guide the farmer to take measures to avoid or control the disease.

\section{BENEFIT TO FARMER USING WRAESEIC}

\subsection{Diagnosis of crop disease}

Farmers can diagnose their crops diseases using expert system so they need not to visit pest control specialist and they could save time and money

\subsection{Irrigation schedule}

They can manage irrigation for their farm which required different on variety of crops, so they can plan for irrigation.

\subsection{Selecting proper pest control}

By observing crop disease symptoms they can select proper pesticide for their disease which will increase productivity.

\subsection{Selecting fertilizer and their quantity}

Depending on soil nutrient condition they can select proper fertilizer and their quantity for their crop.

\section{CONTRIBUTION TO INDIAN SOCIETY}

Agriculture is the dominant sector of Indian economy, which determines the growth and sustainability. About 65 per cent of the population still relies on agriculture for employment and livelihood. India is the first in the world in the production of milk, pulses; second in rice, wheat, sugarcane, groundnut, vegetables, fruits and cotton production; and is a leading producer of spices and plantation crops as well as livestock, fisheries and poultry. In the past few years, Indian agriculture has done remarkably well in terms of output growth. The 11th Five Year Plan (2007-12) witnessed an average annual growth of 3.6 per cent in the gross domestic product (GDP) from agriculture [25].

By improving and implementing technological lead farmer it will add more growth in GDP and help to reduce poverty in rural India as it is major factor which affecting Indian economy growth in global market.

\section{CONCLUSION}

As in India out agriculture sector, rural parts far behind as compared with urban; the ratio of poverty due to the less productivity has increased in rural areas and the major part of Indian Agriculture Sector has covered in rural areas. In the expert system approach for Agriculture have wide range of application in the rural areas of agriculture sector to improve their productivity by implementing the expert system centre for agriculture information and advisory. This system can be very useful in rural India where farmer are not aware about emerging technology in the field of agriculture. In this proposed research work, the objective is to provide the recent technology up to remote areas of India by which The rural farmer will be able to: i) Increase their productivity of crop which can be useful to decrease the poverty ratio in the filed of agriculture, ii) The system will provide proper management of farming in their place, iii) System will make rural farmer familiar and use to with technology iv) The system will give accurate and proper result over traditional method result.

\section{REFERENCES}

[1] Huang Yi, "Research on Internet-based Open Remote Fault Diagnosis Expert System", First Asian Himalayas International Conference on Internet, Kathmandu, 2009

[2] Shenggen Fan, Connie Chan-Kang, and Anit Mukherjee "Rural and Urban Dynamics and Poverty: Evidence from China and India" International Food Policy Research 
Institute, FCND Discussion Paper 196 DSG Discussion Paper 23, 2005

[3] Nidhi Dwivedy, "Challenges faced by the Agriculture Sector in Developing Countries with special reference to India", International Journal of Rural Studies (IJRS), vol. 18 no. 2 Oct 2011, Article 4 Page 1 of 6

[4] O.C. Agbonifo, D.B.Olufolaji "A Fuzzy Expert System for Diagnosis and Treatment of Maize Plant Diseases", International Journal of Advanced Research in Computer Science and Software Engineering, Volume 2, Issue 12,December2012, SSN: 2277 128X

[5] Davenport, H. Thomas and P. Lawrence, "Working Knowledge: How Organizations Manage What They Know". Boston: Harvard Business School Press, 1997.

[6] P. Jackson, "Introduction to Expert Systems," 3rd edition, New York: Addison-Wesley, ISBN 10-20187686-8, 1998.

[7] Doraisamy P., Asstt. Prof, "Concept of an Expert System and Its Application to Agricultural Research", Year: 1994, Volume: 18, Issue: 3 and 4

[8] B. G. Jagyasi, A.K. Pande, R. Jain, "Event based Experiential Computing in Agro-Advisory System for Rural Farmers", IEEE First International Workshop on Wireless Communication and Networking Technologies for Rural Enrichment, pp 439-444, 2011.

[9] Durkin, John, Ohio Journal of Science: Volume 90, Issue 5 (December, 1990).

[10] Peter J. M ellalieu, Karend Turner, "Expert System for Agricultural Production", NZOFt Volume 14 Number 1, January 1986.

[11] A. S. Rao, S. Srivastava, K. Singh, N. Raju, A. Rathore, and R. Samanta, "Soil test crop response based fertilizer recommendation software,"March 2009, url: http://www.iiss.nic.in/stcr/Default.asp.

[12] J. Panchard, S. Rao, M. S. Sheshshayee, P. Papadimitratos, S. Kumar, and J.-P. Hubaux, "Wireless sensor networking for rain-fed farming decision support," in NSDR '08: Proceedings of the second ACMSIGCOMM workshop on Networked systems for developing regions. New York, NY, USA: ACM, 2008, pp. 31-36.

[13] S. A. Al-Kufaishi, "Precision irrigation," Master's thesis, Department of Agricultural Sciences, The Royal Veterinary and Agricultural University, February 2005.

[14] M. John, M. Paul, G. S. Mayura, P. Wei, H. Daniel, and T. Andrew, "Wireless sensor network deployment for water use efficiency in irrigation," in REALWSN '08: Proceedings of the workshop on Real-world wireless sensor networks. New York, NY, USA: ACM, 2008, pp. $46-50$.
[15] S. Neelamegam, C. P. R. G. Naveen, M. Padmawar, U. B. Desai, S. N. Merchant, and V. Kulkarni, "Agrisens: Wireless sensor network for agriculture - a sula vineyard case study," in Proc. 1st International Workshop on Wireless Sensor Network Deployments, Santa Fe, New Maxico, USA, June 2007.

[16] J. Burrell, T. Brooke, and R. Beckwith, "Vineyard computing: Sensor networks in agricultural production," IEEE Pervasive Computing, vol. 3, no. 1, pp. 38-45, 2004.

[17] A. Baggio, "Wireless sensor networks in precision agriculture," In ACM workshop Real-World Wireless Sensor Networks, Stockholm, 2005.

[18] T. Wark, P. Corke, P. Sikka, L. Klingbeil, Y. Guo, C. Crossman, P. Valencia, D. Swain, and G. Bishop-Hurley, "Transforming agriculture through pervasive wireless sensor networks," IEEE Pervasive Computing, vol. 6, no. 2, pp. $50-57,2007$.

[19] B. G. Jagyasi, A.K. Pande, R. Jain, "Event based Experiential Computing in Agro-Advisory System for Rural Farmers", IEEE First International Workshop on Wireless Communication and Networking Technologies for Rural Enrichment, pp 439-444, 2011.

[20] Nidhi Dwivedy, "Challenges faced by the Agriculture Sector in Developing Countries with special reference to India", International Journal of Rural Studies (IJRS), vol. 18 no. 2 Oct 2011, Article 4, pp. 1 to 6 .

[21] K. Robindro, S. Kr. Sarma, "JESS Based Expert System Architecture For Diagnosis Of Rice Plant Diseases: Design And Prototype Development", IEEE 4th International Conference on Intelligent Systems, Modelling and Simulation, 2013.

[22] Panjab Singh, Indian Agricultural Development in Changing Scenario Past, Present and Future, JOURNAL OF THE INDIAN SOCIETY OF AGRICULTURAL STATISTICS.

[23] L. V. Madden, G. Hughes, and F. van den Bosch, The Study of Plant Disease Epidemics. The American Phytopathological Society, APS Press,St. Paul, Minnesota 55121, U.S.A., 2007.

[24] A. Pande, B. G. Jagyasi, and R. Choudhuri, "Late blight forecast using mobile phone based agro advisory system," in Proc. third Internation Conference on Pattern Recognition and Machine Intelligence, PReMI 2009, Dec 2009.

[25] http://www.ibef.org/industry/agriculture-india.

[26] N. D. Katkamwar, B. Kumar, K.Kalaskar, An Expert System Approach for Improvement of Agriculture Decision, Singaporean Journal of Scientific Research, Vol5.No.1,pp8-12. 